\title{
The COVID-19 pandemic and epidemiologic insights from recession-related suicide mortality
}

\author{
Tarun Bastiampillai ${ }^{1,2} \cdot$ Stephen Allison ${ }^{2} \cdot$ Jeffrey C. L. Looi $\mathbb{i}^{3} \cdot$ Julio Licinio ${ }^{4} \cdot$ Ma-Li Wong $\mathbb{D}^{5} \cdot$ Seth W. Perry ${ }^{5}$
}

Received: 22 May 2020 / Revised: 17 July 2020 / Accepted: 21 August 2020 / Published online: 1 September 2020

(c) Springer Nature Limited 2020

The COVID-19 pandemic has led to the initiation of largescale quarantine measures, resulting in widespread closures of significant sectors of the worldwide economy. The International Monetary Fund predicts that the world economy will experience the worst recession since the Great Depression, labelling this the "Great Lockdown" [1]. In this context, we need to plan for deleterious mental health effects resulting from this global recession, including: job stress and insecurity, sharply rising unemployment and longer duration of unemployment, income shock, bankruptcy, rising household debt levels, marked decline in asset values, loss of savings, house repossessions, reduced healthcare resources, cuts in community and social services, strained relationships, increased social isolation, and rises in alcohol misuse [2]. In 1897, Durkheim proposed that periods of significant economic, social or political change might result in 'anomic suicide' due to a lack of social integration, and a rise in concern for self-interest, as people's material and social circumstances fall well below

Supplementary information The online version of this article (https:// doi.org/10.1038/s41380-020-00875-4) contains supplementary material, which is available to authorized users.

Tarun Bastiampillai

Tarun.bastiampillai@monash.edu

1 Department of Psychiatry, Monash University, Wellington Road, Clayton, VIC 3800, Australia

2 College of Medicine and Public Health, Flinders University, Adelaide, SA 5042, Australia

3 Academic Unit of Psychiatry and Addiction Medicine, Australian National University Medical School, Canberra Hospital, Canberra, ACT, Australia

4 Departments of Psychiatry, Pharmacology, Medicine and Neuroscience and Physiology, College of Medicine SUNY Upstate Medical University, Syracuse, NY 13210, USA

5 Departments of Psychiatry, and Neuroscience \& Physiology, College of Medicine SUNY Upstate Medical University, Syracuse, NY 13210, USA their previous living standards [3]. Public health measures necessitated by COVID-19 may thus drive the development of anomie, which has repercussions for social connectedness, overall mental health and specific adverse consequences such as increased suicide rates. There are emerging concerns that the COVID-19 pandemic may specifically increase suicide rates due to the combination of economic stress, social isolation, barriers to receiving mental health treatment and increased levels of national anxiety [4]. Accordingly, epidemiological data on suicide from previous significant economic recessions and depressions may help estimate the potential economic impacts of COVID-19 on suicide rates.

\section{Economic recessions, unemployment and suicide rates}

It is well established that economic recessions are associated with increases in suicide, particularly for working age men [2]. These data come from time-series analyses and cross-sectional correlative studies from many countries. US data between 1928 and 2007 reveal that suicide rates rise with economic contractions and fall with economic expansions [5]. Research consistently identifies links between economic recession and unemployment, and suicide, but the evidence for other mechanisms beyond unemployment are less clear [2]. The unemployed are 2-3 times more likely to die by suicide compared to those who are employed [2]. This association between unemployment and suicide holds even after controlling for the effects of mental illness and socioeconomic variables [2].

In the recent Global Financial Crisis (GFC) of 2008, suicide rates increased by $4.2 \%$ in 27 European countries and by $6.4 \%$ in 18 American countries, with more marked increases noted for men [6]. In this comprehensive study of 45 countries, it was estimated that there were 4884 excess suicides in 2009 , compared to the 


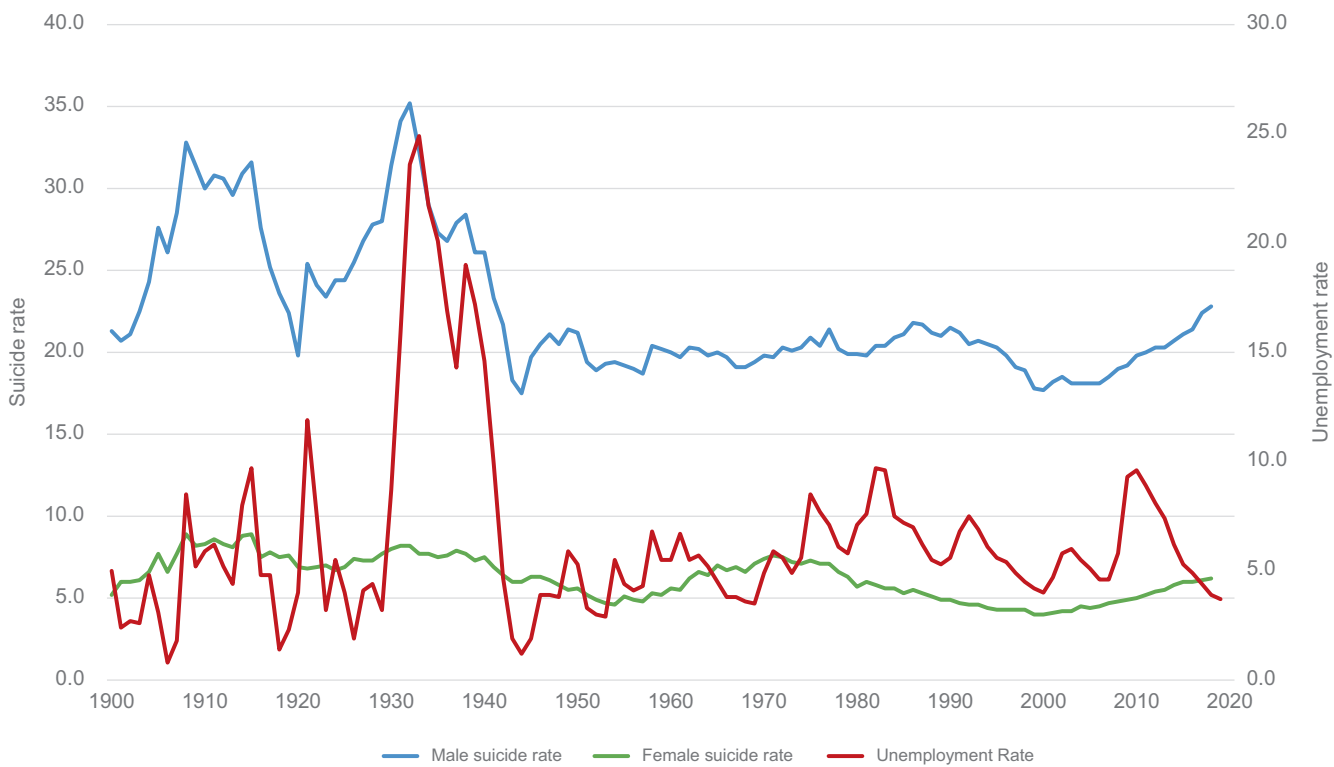

Fig. 1 USA age adjusted suicide rates and unemployment rates since 1900. USA age-adjusted suicide rates per 100,000 for total persons, males and females between 1900 and 2018 and unemployment rates 1900 to 2019 (see Supplementary file for data sources).

baseline period from 2000 to 2007. Another analysis covering more than 63 countries from the World Health Organisation database between 2000 and 2011 (which includes the GFC), identified that an increase in the unemployment rate from 3 to $6 \%$ corresponded with a $6.1 \%$ increase in suicide rates, compared to only a $2.2 \%$ increase in suicide rate if unemployment levels increased from 12 to $15 \%$ [7]. Therefore, the relationship between unemployment levels and suicide rates is non-linear, with higher rises in suicide rates in countries with lower compared to higher baseline unemployment rates prior to the GFC, which the authors argue may be due to unexpected rises causing more fear/insecurity [7], i.e. increased anomie as Durkheim proposed. Stuckler et al. [8] reported that within European Union (EU) countries between 1970 and 2007, every 1\% increase in unemployment rate was associated with a $0.79 \%$ increase in suicide rate for those aged under 65 . They also showed that mass unemployment events associated with greater than $3 \%$ rises in unemployment were associated with a $4.45 \%$ increase in suicides for those aged under 65 . In the US, a similar analysis conducted between 1999 and 2010 (covering the GFC period) revealed that a $1 \%$ increase in unemployment is associated with a $0.99 \%$ increase in suicide rates at the state level [9]. The higher impact of rising unemployment on suicide rates in the USA compared to Europe may be attributable to reduced labour market social welfare programs (e.g. providing financial, social support and job opportunities) and ready availability of firearms [9].

\section{The "Great Depression" and suicide rates in USA, Canada, England and Australia}

Given the numerous predictions that this latest downturn may be the worst experienced since the Great Depression of the 1930s, we have specifically analysed the available data on suicide deaths in this time period for USA (see Fig. 1), Canada, England and Australia (Anglosphere countries). The Great Depression began in 1929, leading to acute and sustained rises in unemployment (averaging over 10\%) in all these countries throughout the 1930s.

The Great Depression time-series data (see Supplementary for more details) between 1929 and 34, across these four countries reveals an average peak suicide rate increase of $16 \%$, with most of this peak increase accounted for by a $19 \%$ rise in the male peak suicide rate versus a $9 \%$ rise in the female peak suicide rate.

\section{Conclusion}

Worldwide suicide rates have declined $32.7 \%$ from 1990 to 2016 [10], so there is a lower overall baseline rate and the context of improved economic circumstances prior to COVID-19, but paradoxically, Durkheim's anomie and the evidence cited above suggest this may heighten the impact of the related economic recession on suicide rates. If the COVID-19 pandemic results in a financial crisis equivalent to the GFC (which is an optimistic forecast), then suicide rates could rise by $5 \%$ in middle to high income countries. 
Alternatively, as is likely, if the COVID-19 pandemic results in another "Great Depression" with unemployment rates increasing by $15-20 \%$, then historical epidemiologic data indicate that suicide rates may rise by $\sim 15 \%$, with working age men being the highest risk group. Relative to the UK, Australia, Canada and many European countries, the US may be more susceptible to increased suicide rates stemming from mass unemployment due to relative differences in government welfare provisions. Intervention is necessary to mitigate the likelihood of adverse mental health outcomes and increased suicide mortality consequent to this unprecedented healthcare crisis and resultant acute economic shock.

\section{Compliance with ethical standards}

Conflict of interest The authors declare that they have no conflict of interest.

Publisher's note Springer Nature remains neutral with regard to jurisdictional claims in published maps and institutional affiliations.

\section{References}

1. International Monetary Fund. World Economic outlook, April 2020: The Great Lockdown. https://www.imf.org/en/Publica
tions/WEO/Issues/2020/04/14/weo-april-2020. Accessed 15 May 2020.

2. Haw C, Hawton K, Gunnell D, Platt S. Economic recession and suicidal behaviour: possible mechanisms and ameliorating factors. Int J Soc Psychiatry. 2015;61:73-81.

3. Durkheim E. Le suicide: etude de sociologie. Bar-le-Duc. France: Imprimerie Contant-Laguerre; 1897.

4. Reger MA, Stanley IH, Joiner TE. Suicide mortality and coronavirus disease 2019-a perfect storm? JAMA Psychiatry. 2020. https://doi.org/10.1001/jamapsychiatry.2020.1060.

5. Luo F, Florence CS, Quispe-Agnoli M, Ouyang L, Crosby AE. Impact of business cycles on US suicide rates, 1928-2007. Am J Public Health. 2011;101:1139-46.

6. Cheng S, Stuckler D, Yip P, Gunnell D. Impact of 2008 global economic crisis on suicide: time trend study in 54 countries. BMJ. 2013;347:f5239.

7. Nordt C, Warnke I, Seifritz E, Kawohl W. Modelling suicide and unemployment: a longitudinal analysis covering 63 countries, 2000-11. Lancet Psychiatry. 2015;2:239-45.

8. Stuckler D, Basu S, Suhrcke M, Coutts A, McKee M. The public health effect of economic crises and alternative policy responses in Europe: an empirical analysis. Lancet. 2009;374:315-23.

9. Reeves A, Stuckler D, McKee M, Gunnell D, Chang SS, Basu S. Increase in state suicide rates in the USA during economic recession. Lancet. 2012;380:1813-4.

10. Naghavi M. Global burden of disease self-harm collaborators. Global, regional, and national burden of suicide mortality 1990 to 2016: systematic analysis for the Global Burden of Disease Study 2016. BMJ. 2019;364:194. 